\title{
CIRURGIA AMBULATORIAL - EXPERIENNCIA DA LIGA DE CIRURGIA AMBULATORIAL DO CENTRO ACADÉMICO OSWALDO CRUZ DA FACULDADE DE MEDICINA DA UNIVERSIDADE DE SÃO PAULO
}

\author{
Aldo Junqueira Rodrigues Jr. * \\ Elisa Yamamuro** \\ Mauro M. Speranzini*** \\ Manlio B. Speranzini**** \\ Mario Ramos de Oliveira*****
}

Resumo - o sucesso e a crescente valorização dos Centros de Cirurgia Ambulatorial, nos últimos anos, vem aumentando o elenco de operaçōes passíveis de serem realizadas a nivel ambulatorial.

Neste contexto, a Liga de Cirurgia Ambulatorial representa uma nova filosofia de ensino aplicável em instituição universitária no sentido de proporcionar ao acadêmico de Medicina, habilidade profissional para solucionar parte considerável das necessidades de sua comunidade.

Foram realizadas 169 operaçōes, pela Liga de Cirurgia Ambulatorial, no periodo de julho de 1986 a março de 1987, coordenada e supervisionada diretamente por docentes da $3^{a}$ Cllinica Cirúrgica do Hospital das Clínicas da Faculdade de Medicina da Universidade de São Paulo (Serviço do Prof. Mário Ramos de Oliveira).

Nesta casuística não se observou nenhuma complicação no ato operatório. $82,24 \%$ dos casos operados foram seguidos até a alta ambulatorial. Houve 20 complicaçōes pós-operatórias sendo duas de natureza infecciosa.

\section{Introdução}

A Cirurgia Ambulatorial ou cirurgia do paciente externo atualmente representa modalidade de tratamento cirúrgico aplicável a diferentes comunidades. Sua aceitação, principalmente na última década, foi obtida pelo baixo indice de complicaçōes, intra e pós-operatórias, aliado à diminuição do custo da atenção médica.

O elenco de procedimentos cirúrgicos do âmbito da Cirurgia Ambulatorial é vasto. Decorre que uma grande parcela deste, caracterizando-se pela sua simplicidade, fica ao alcance do estado cognitivo e das habilidades psicomotoras do acadêmico de Medicina. ${ }^{6}$

Muitos destes procedimentos "simples" são necessários para a formação do médico geral e visam a solução de parte considerável das necessidades de sua futura clientela. ${ }^{4}$

(") Professor Livre Docente do Departamento de Cirurgia da Faculdade de Medicina da Universidade de Săo Paulo.

("*) Acadêrnica da Faculdade de Medicina da Universidade de São Paulo. Presidente da Liga de Cirurgia Ambulatorial.

(***) Acadêmico da Faculdade de Medicina da Universidade de Såo Paulo. Ex-Presidente da Liga de Cirurgia Ambulatorial.

( m-) Professor Adjunto da Disciplina de Cirurgia Geral da Faculdade de Medicina da Universidade de Săo Paulo.

(*.***) Professor Titular da Disciplina de Cirurgia Geral da Faculdade de Medicina da Universidade de Såo Paulo.
A $3^{\text {a }}$ Clínica Cirúrgica $\left(3^{\text {a }} \mathrm{CC}\right)$ do Hospital das Clínicas $(\mathrm{HC})$ da Faculdade de Medicina da Universidade de São Paulo (FMUSP) (Serviço do Prof. Mário Ramos de Oliveira), desde 1983 vem coordenando as atividades da Liga de Cirurgia Ambulatorial (LCA), entidade universitária integrada pelos acadêmicos $4^{\circ}$ anistas de graduação do curso médico da FMUSP, que está sob orientação direta de um docente da clínica.

Doze acadêmicos são selecionados após concurso de inscrição voluntária, composto de prova escrita e entrevista. São considerados pré-requisitos o curso de graduaçåo, o de Propedêutica Cirúrgica e o de Extensảo Universitária, de Cirurgia Ambulatorial, no qual alguns tópicos do assunto são discutidos.

Foram estabelecidas regras, para seleção do paciente cirúrgico, escolha do procedimento operatório e dos cuidados pós-operatórios, visando a orientação dos acadêmicos, para quem, muitas vezes, esta situação representa o primeiro contato com o paciente cirúrgico. As intervençōes são realizadas no Setor de Cirurgia Ambulatorial da 3․ CC, ou seja, no Centro Cirúrgico Ambulatorial do prédio dos Ambulatórios do HC/FMUSP.

Após três anos de trabalho, tendo como base as "Normas e Condutas da LCA", procuramos avaliar a eficiência da sua atividade através de um estudo prospectivo de casos operados na LCA no período de julho de 1986 a março de 1987.

As indicaçōes destas operaçōes obedeceram aos critérios de seleção e de elaboração diagnóstica conforme já estabelecidos em comunicaçōes ànteriores. ${ }^{9},{ }^{10}$.

\section{Casuistica e Método}

Foram realizadas 169 operaçōes pela LCA (média de 14 intervençōes por aluno) no periodo de julho de 1986 a março de 1987 (Tabela 1).

Durante a triagem do paciente, após exame físico, é preenchido prontuário (Esquema 1) no qual são anotados, além dos dados pessoais, o resumo da observação clínica, a hipótese diagnóstica e a indicação da terapêutica cirúrgica. Ainda nessa primeira entrevista é marcada a data de operação e o horário em que o paciente comparece ao Ambulatório, além da orientação higiênico-dietética pertinente.

No dia da cirurgia, o paciente é avaliado quanto aos parâmetros vitais, estado emocional e observação da orientação higiênico-dietética.

No ato operatório, foi padronizado como anestésico local, a Lidocaína diluída a $1 \%$ sem adrenalina para blo- 
Tabela 1 - Cirurgias realizadas na LCA no periodo de julho de 1986 a março de 1987.

\begin{tabular}{llr}
\hline CIRURGIA & No & $\%$ \\
\hline Exérese de cisto sebáceo & 51 & 30,17 \\
Exérese de lipoma & 25 & 14,79 \\
Plástica de freio curto balanoprepucial & 17 & 10,05 \\
Exérese de projétil detonado de arma de fogo & 16 & 9,46 \\
Exérese de granuloma de corpo estranho & 15 & 8,87 \\
Postectomia & 10 & 5,91 \\
Exérese de unha encravada & 06 & 3,55 \\
Exérese de cisto pilonidal & 04 & 2,36 \\
Exérese de fibroma subcutåneo & 04 & 2,36 \\
Exérese de gånglio & 04 & 2,36 \\
Exérese de verruga & 04 & 2,36 \\
Exérese de corpo estranho & 03 & 1,77 \\
Exérese de quelరide & 02 & 1,18 \\
Exérese de calosidade & 01 & 0,59 \\
Plástica de ginecomastia & 01 & 0,59 \\
Exérese de hamartoma vascular & 01 & 0,59 \\
Exérese de hemangioma capilar & 01 & 0,59 \\
Exérese de nevus epidérmico & 01 & 0,59 \\
Exérese de nódulo reumático subcutåneo & 01 & 0,59 \\
Exérese de nódulo subcutåneo (linfangite crônica granulomatosa) & 0,59 \\
Exérese de queratose seborreica & 0,59
\end{tabular}

\section{Tabela 2 - Complicaçēs sem infecção}

DEFEITOS CLINICOS DA CICATRIZAÇĀO

№ DE CA-
SOS

\section{Serosidade}

04

2,87

Hematoma

02

1,43

Deiscência parcial

09

6,47

Secreção serosanguinolenta

01

0,71

Necrose superficial das bordas

02

1,43 
queio ou infiltraçāo zonal (na quantidade nāo superior a 20 mg); para hemostasia e sutura do tecido celular subcutâneo, fios de catgut "3-0" simples; para sutura da pele, pontos simples ou "Blair-Donnatti" de "mononylon" "4-0" ou "5-0". Após o ato cirúrgico, o paciente retorna a sua residência por seus próprios meios. É norma da Liga prescrever analgésico a todos os pacientes no pós-operatório imediato. É também obrigatório o pedido de exame anátomo-patológico. Nesse sentido, especial atençāo é dada ao preenchimento dos vários itens que compōem a ficha de encaminhamento do exame, bem como proporcionar as melhores condiçōes de fixaçāo do espécime retirado.

Nāo utilizamos antibiótico profilático.

Ao término da cirurgia, o acadêmico acrescenta prontuário da Liga (Esquema 1), a descriçāo da cirurgia.

O paciente recebe orientaçōes gerais sobre a oportunidade da troca de curativo, a higiene da regiāo operada e orientaçāo das possivveis complicaçōes. Caso estas ocorram, é instruído para procurar o Serviço antes do retòrno previsto.

O primeiro retorno após a cirurgia é realizado, em geral, no $7^{\circ}$ dia pós-operatório, ocasiāo que preconizamos a retirada dos pontos de pele. Fazem exceçāo, operaçōes sobre a face que terāo retornos mais precoces entre $02^{\circ}$ e o $4^{\circ}$ dias do pós-operatório. É norma da Liga fazer no minimo dois retornos, ficando a cargo do Acadêmico, em caso de necessidade e supervisionado por docente, acrescentar eventuais retornos.

Os dados clínicos e as condutas tomadas durante 0 seguimento deverāo constar na folha de evoluçāo, no verso do prontuário da Liga (Esquema 1).

O retorno é previamente agendado, anotando-se a data e observaçōes necessárias no livro de retornos próprio da Liga.

As trocas de curativos do paciente após exame da ferida cirúrgica foram padronizadas conforme referido. ${ }^{9}$

Semanalmente sāo realizadas reuniōes da Liga de Cirurgia Ambulatorial com a participaçāo de todos os membros da Liga, onde, além de aulas teóricas e seminários sobre temas relacionados à Cirurgia Ambulatorial, sāo discutidas complicaçōes das operaçōes realizadas, sob a orientaçāo do coordenador da Liga de Cirurgia Ambulatorial.

\section{Resultados}

Em nenhum dos pacientes operados pudemos observar, durante o ato cirúrgico, complicaçōes decorrentes da anestesia local.

Dos 169 casos operados, apenas 30 (17,75\%) nāo compareceram ao primeiro retorno. Assim, serāo apresentadas as evoluçōes dos 139 casos que foram seguidos até a alta definitiva.

Vinte casos evoluíram com complicaçōes, divididas em dois grupos: 18 casos (12,94\%) que caracterizaram defeitos clínicos de cicatrizaçāo sem infecçāo (Tabela 2), e dois casos $(1,43 \%)$ com infecçāo: um com deiscência parcial e supuraçāo de subcutâneo; outro com abscesso subcutâneo. O exame bacteriológico revelou Staphylococcus aureus no primeiro caso e bacilo negativo no segundo caso.

O número de retornos necessários foi analisado. Assim, para os casos de evoluçāo sem intercorrência, é norma haver dois retornos: o $1^{\circ}$ para retirada de pontos de pele e $02^{\circ}$ em torno do $14^{\circ}$ dia do pós-operatório para reavaliação e alta. Nos casos que evoluiram com complicaçāo sem infecçāo, a média foi de três retornos enquanto que naqueles com infecçāo houve necessidade de quatro retornos.

\section{Comentários}

A Cirurgia Ambulatorial como tratamento médico necessita desempenhar o seu papel com desenvoltura $e$ segurança.

A análise de cada caso deve ser ainda mais criteriosa para que o paciente desfrute de condiçōes semeIhantes às obtidas no regime de internaçāo.

Atualmente, no planejamento cirúrgico eletivo para determinada comunidade nāo é possivel prescindir da utilizaçāo da Cirurgia Ambulatorial.

Nesse trabalho, 169 casos foram operados por acadêmicos, $4^{\circ}$ anistas da FMUSP, orientados diretamente por docentes da 3 ¿ CC. Evidentemente, a proposiçāo de oferecer treinamento em cirurgia ao $4^{\circ}$ anista de Medicina nāo é tarefa desprovida de preocupaçāo, justificando-se por isso nas indicaçōes dos casos operados a relativa simplicidade e superficialidade dos procedimentos, uma vez que se tratava do primeiro contato destes alunos com o doente cirúrgico. definitiva.

Dos 169 operados, 139 foram seguidos até a alta

retorno de $82,24 \%$ dos pacientes pode ser considerado em nosso meio um nivel bastante satisfatório.

$\dot{E}$ importante assinalar que isso se deve, principalmente, à real participaçāo do acadêmico, cujo interesse e dedicaçāo permitiram estabelecer, de modo marcante e estreito, a relaçāo médico-paciente.

O objetivo primordial da LCA é o de propiciar ao acadêmico, a possibilidade de praticar o ato médico na sua plenitude, exercitando a anamnese, a propedêutica, a elaboraçāo do diagnóstico clínico e a indicaçāo da operaçāo, e a sua realizaçāo, a prática dos cuidados pós-operatórios normais, o tratamento das complicaçōes e a avaliaçāo dos critérios de alta.

A LCA é fruto da iniciativa, motivaçāo e inquietude próprias do acadêmico que, prevendo ser a prática médica de fundamental importância na sua formaçāo profissional, associa ao mesmo tempo este legítimo anseio à prestaçāo de serviço à comunidade que the serve de suporte. Nesse sentido, coube à $3^{\text {a }}$ CC compreender essa justa reinvidicaçāo e oferecer o apoio e a orientaçāo que a iniciativa necessitava.

No tratamento cirúrgico ambulatorial, a avaliaçāo pré-operatória do paciente é fator decisivo e, nessas condiçōes, devemos concordar com BATTAGLIA (1983) para quem "qualquer procedimento que nāo invada as cavidades naturais maiores do organismo, exceto a laparoscopia e a hernioplastia, podem ser consideradas passiveis de tratamento cirúrgico ambulatorial, se os critérios assim o permitirem"8.

Indubitavelmente, nossos bons resultados decorrem da observaçāo dos critérios normativos de seleçāo do paciente estabelecidos em "Normas e Condutas da LCA" .

Nossa experiência na LCA não é diferente da de outros Centros de Cirurgia Ambulatorial ${ }^{\natural}$. Nāo foram aqui também observados nenhum acidente cardiovascular ou necessidade de transfusāo de sangue ou derivados, nem 
LI C A DE C I A U A C I A A N P U L A T O H I A L

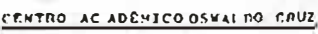

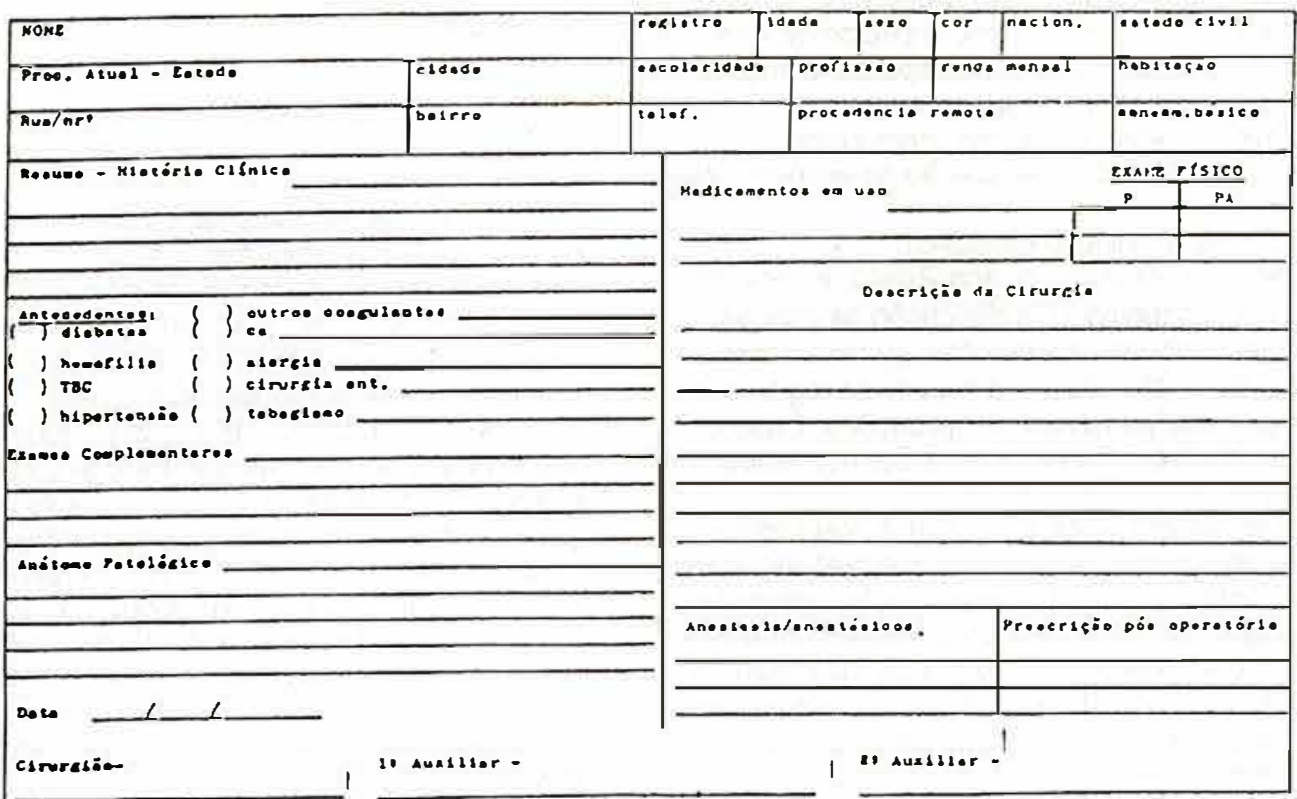

FRENTE

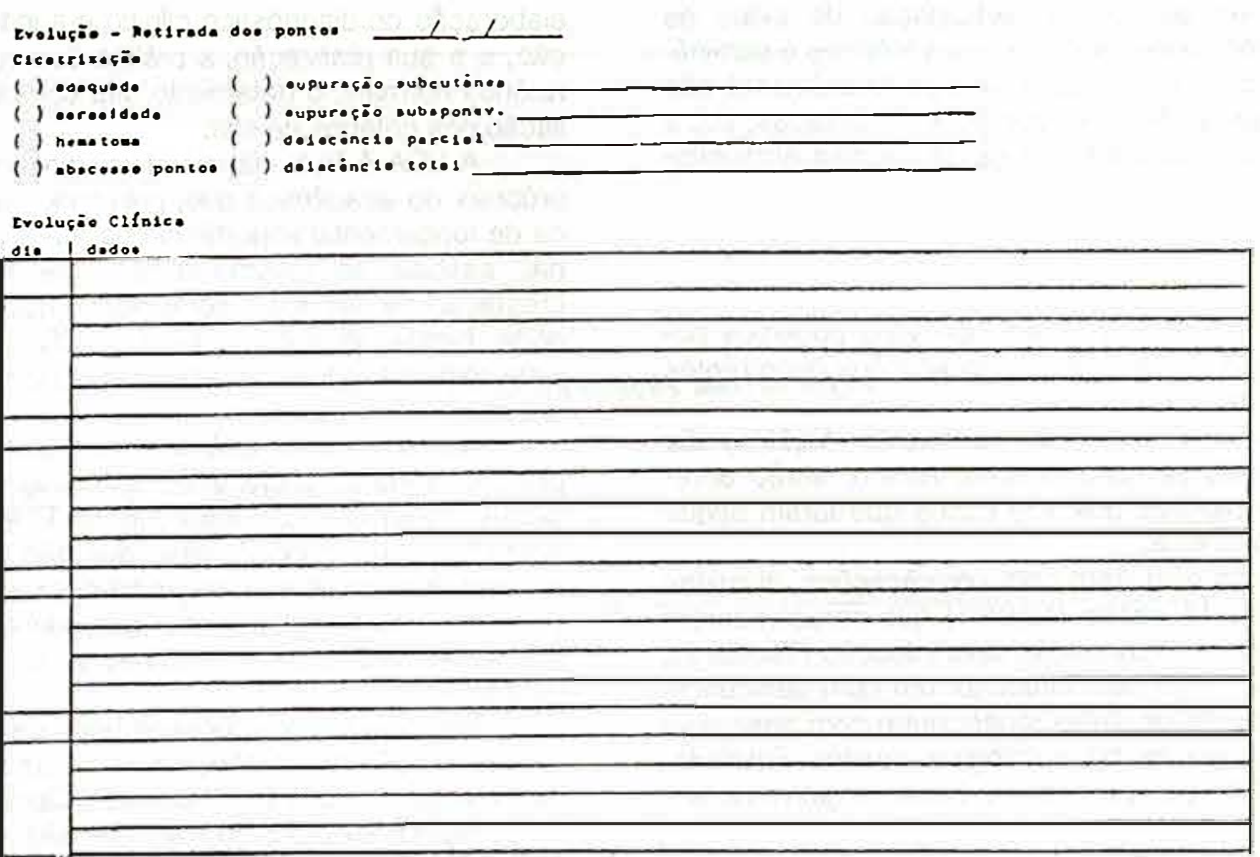


Cirurgia ambulatorial - experiéncia da liga de cirurgia ... .

transferência do paciente operando para unidades de internaçāo.

Um serviço de cirurgia pode ser avaliado sob outros aspectos; entre estes, o indice de complicaçōes pós-operatórias infecciosas, em cirurgias limpas, constitui fator de particular relevância.

A redução do indice de infecção pós-operatória, tanto no paciente jovem como no paciente idoso, sem necessitar técnicas ou equipamentos sofisticados, tem sido uma das mais importantes vantagens da Cirurgia Ambulatorial.

Já em 1968, OTHERSEN \& CLATWORTHY' mostraram que a taxa de infecção, tanto respiratória como do trato gastrointestinal, era reduzido de 50 a $70 \%$ quando as cirurgias eram realizadas a nivel ambulatorial.

No Shouldice Hospital, instituição que desde 1945 propōe para hérnias inguinais um tratamento cirúrgico em regime ambulatorial, a taxa de infecção observada foi de $0,5 \%$.

Note-se que nesse e em outros serviços ${ }^{3}, 50$ ato cirúrgico é realizado sempre por cirurgiōes experientes e devidamente treinados. De forma que a existência de 2 complicaçōes infecciosas em 139 pacientes operados por acadêmicos, em fase inicial de treinamento, não surpreende e, de qualquer forma, atesta o padrão de qualidade obtido, e que ainda pode ser melhorado.

Com as ressalvas já assinaladas, podemos afirmar que a possibilidade do acadêmico de $4^{\circ}$ ano realizar 14 intervençōes e participar em 30 , sob orientação docente, é opção válida, desprovida de complıcaçōes graves e com niveis de complicaçōes compativeis e aceitáveis, concernente ao ato médico. Relativo à formação profissional é iniciativa adequada ao acadêmico, ao ensejar a prática médica na sua plenitude e que tem trazido grande satisfação ao aluno.

Abstract - The growing sucess as well as the wide recognition of the Out Patient Surgery Centers as a medical entity in the past few years have given a rather substancial contribution towards the further development of ambulatory surgical care.

In this fashion, the "Liga de Cirurgia Ambulatorial" represents a new trend in the medical training field proportionating medical students skills to attend the community's demands.

A total of 169 outpatient surgeries were performed by 12 medical students between June 1986 and March 1987 under the coordination and supervision of assistant professor of the " 3 a Clinica Cirúrgica do Hospital de Clínicas da Faculdade de Medicina da Universidade de Sâo Paulo".

No Complications took place during the surgical procedure. As many as $82,4 \%$ of all operated patients had a complete follow up before definitive dismissal.

Only two cases out of a total of twenty with different postoperative complications were infectious.
Referências Bibliográficas

01. ALEXANDER, M. A. J. How to select suitable procedures for outpatient surgery; the Shouldice Hospital experience. Bull. Amer. Coll. Surg., 71:7-11, 1986.

02. DAVIS, J. E. \& DETMER, D. E. The ambulatory surgical unit. Ann. Surg., 175:556-9, 1972.

03. DAVIS, J. E. Ambulatory surgical care; basic concept and review of 1,000 patients. Surgery, 73:483-5, 1973.

04. LÁZARO DA SILVA, A. A cirurgia em nivel ambulatorial. Rev. Assoc. méd. bras., 30:170-1, 1984.

05. NATOF, H. E. Complications associated with ambulatory surgery. J. Amer. med. Ass., 244:1116-8, 1980.

06. OLIVEIRA, M. R.; SPERANZINI, M. B.; RODRIGUES JR., A. J. A atualidade da cirurgia ambulatorial. Rev. bras. Educ. Méd., 9:52-54, 1985.

07. OTHERSEN Jr., H. B. \& CLATWORTHY Jr., H. W. Outpatient herniorrhaphy for infants. Amer. J. Dis. Chil., 116:78-80, 1968.

08. POLAND, V. Strategies for ambulatory surgery. Aorn. J., 39:1245, 1248-9, 1252-3, 1984.

09. RODRIGUES Jr., A. J.; YAMAMURO, E. M.; SPERANZINI, M. M.; MAKSOUD Fo. J. G. Normas e condutas da Liga de Cirurgia Ambulatorial. São Paulo, 1986. Publicação particular.

10. RODRIGUES Jr., A. J.; TAKEUTI, M. M.; SZAJNBOK, I.; KAMIKAWA, J.; LIN, O.; YAMAMURO, E. M. Normas de avaliaçāo pré-operatória do paciente de cirurgia ambulatorial; uma proposta da Liga de Cirurgia Ambulatorial. Rev. Med., 67(2):37-9, 1987.

Endereço dos Autores:

Rua Dr. Manoel Maria Tourinho, 952

Pacaembú

01296 - São Paulo, SP 